\title{
Modern Hand-Grenades
}

\author{
The Aasen Hand, Rifle and Mine Grenade
}

\section{By Major H. Bannerman-Phillips}

THE use of the "grenade" in modern warfare is a revival of an ancient practice, and the term was first
used by DuBilley in reference to the siege of Arles in 1536. Until the end of the seventeenth century soldiers of the line were trained to throw grenades by hand, hence the name "grenadier." The grenades were hollow balls of iron or other metal, or annealed glass, about $2 \frac{11}{2}$ inches in diameter, filled with gun-powder and fired by a fuse which was lighted before throwing them. Sodiers of long service and acknowledged bravery were selected for grenadiers, of whom there were comparatively few in each regiment of infantry at first, though later there were grenadier companies, and still later the "grenadier company" of each battalion took priority on parade in both the English and French armies, though they no longer carried the little spherical projectiles which first gave them their name, and were mainly distinguishable by the height of the men, and their special uniform or head-dress.

Hand grenades were used to a large extent during the Russo-Japanese war, more particularly by both sides when fighting at close quarters during the assaults on the various forts at Port Arthur. The Japanese made them in the form of a small tin cylinder, about 8 inches long and 3 inches.in diameter, filled with a high explosive and with about 7 inches of safety fuse projecting through a hole in the lid. This fuse being lighted before the grenade was thrown would allow about 9 seconds for the missile to reach its destination previous to exploding, but would not burn long enough to allow an enemy to pick it up when fallen and hurl it back before it had done its work. This was, in a manner, harking back to primitive methods, and any small closed tin receptacle wonld serve the same purpose if it were charged with gun-cotton or dynamite and a detonator and fuse attached in the usual way. The effect of these hand grenades when exploded in a confined space is sometimes very deadly. For instance, on one occasion a Russian guard of no less than seventeen men were killed inside a guard room by an improvised grenade, consisting of a fused slab of guncotton which was thrown through one of the windows.

So effective is this class of projectile when used under suitable conditions such as by storming partie

on siege works or in small sorties by the besieged with the object of attacking sap-heads and approaches, that the Japanese found it necessary, when working in the trenches close to the enemy's line, to protect themselves by special wooden frames about 7 feet by 4 fee with stout wire netting projecting above the parapet. It is not to be wondered at therefore if inventors have endeavored of late years to produce grenades which while deadly to the enemy on explosion shall yet be capable of being safely handled by the thrower. The Aasen hand, rifle, and mine grenades are constructed to meet these conditions, as will be seen from the following particulars furnished by the manufacturers. Our cover illustrates both the rifle and howitzer form of the Aasen grenade. Of the illustrations on this page, Fig. 1 shows the manner in which a soldier carries hand grenades on his person; Fig. 2 is a picture of a rolley of howitzer grenades, in which case the grenades are discharged from a fixed stand with various degrees of inclination to the horizon; and Fig. 3 pictures several types of grenades. In a recent number of the Scientific American, the Aasen mine grenade was described and illustrated-a bomb which is prevented from rising above a predetermined height by means of a chain secured in the ground, and electrically fired.

The methods and results of tests carried out with the various forms of weapon and projectile at a private practice range used by the inventor in Copenhagen in Denmark are shown as follows:

$A$. Volleys of rifle grenades were fired by 7 men from behind covers against a group of 80 double-figure targets of wood distributed under cover over an are of 900 square meters. Results of the first volley, as shown by numerals on the targets, 93 hits on 43 tar gets. After the third volley seventy-two targets showed

168 hits. The range varied between 300 and 400 meters The rifle grenade complete weighs about 550 gramme and contains 72 bullets each weighing 2.5 grammes and about 70 grammes of explosive. These 72 projectiles cover an area of at least 40 to 50 square meters. The rifle grenade can be used with an ordinary military rifle at all distances up to about $\mathbf{4 0 0}$ meters. The destructive efficiency of the grenade is due mainly to the fact that the interior percussion mechanism causes $i$ to explode immediately on impact and before the grenade has time to bury itself in the ground.

$B$. Salvoes from seven "howitzers" were fired at a group of 80 figure targets placed within an area of about 900 square meters. The results of the first salvo are shown by numerals recording the hits on each target. After the fourth salvo 68 figure targets had re ceived 143 hits between them. The distances varied between 280 and 310 meters. The grenades used were of type $C$, each weighing 1 kilogramme and containing 215 bullets and 200 grammes of explosive (Ecko). This $C$ type can be thrown by hand up to 40 meters and with the "howitzer" or discharging tube up to 300 meters. The "howitzer" weighs 12 kilogrammes and can be carried in a special case as one would carry a rifle. The bullets cover an area of at least 80 square

che The bullets cover an area of at least 80 square

face. At a distance of 10 meters they will pierce at least 100 millimeters of wood and will kill up to 50 meters. A hundred soldiers can lay out a protective line of these mine grenades 4,000 meters in length in less than two hours.

\section{The Recent Earthquake}

A $\mathrm{T}$ this writing, a few days after the earthquake $A$ of February 10th, it is impossible to present more than a fragmentary account of the occurrence, or to be sure that much of the information now available on the subject is accurate. Even if the disturbance had been far more severe, entaliing immense loss of life and property, we should be in much the same state of uncertainty. As matters now stand in this country, it is nobody's business in particular to collect and digest reports of earthquakes immediately after their occurrence, when all the facts are fresh in the observers' minds, and a high degree of accuracy in the record is therefore attainable. Seismographs are in operation at a few widely scattered points, but there is no systematic and prompt interchange of their records, analogous to the process of assembling meteorological observations by telegraph which has been brought to such perfection by the Weather Bureau. In short, the United States Seismological Service is still only a dream; just as the national weather service was for the far-seeing service was for the far-seeing
American scientists of half a century ago.

The earthquake in question occurred a little after half-past one o'clock in the afternoon. The seismograph at the American Museum of Natural History, in New York, registered preliminary tremors beginning at $1: 33: 5$; the first well marked shock at $1: 33: 25$; the maximum at $1: 33: 45$; and trailers continually until about $1: 35$. The macroseism lasted hardly half a minute. Shocks perceptible to the human senses occurred in eastern Pennsylvania, New Jersey, New York State, New England, and lower eastern Canada. The epicenter appears to have been somewhere in the lower St. Lawrence Valley. So far as may be gathered from press dispatches, it cannot have been very distant from western and northern New York, where the disturbance
reached an intensity of 6 , or pos-

Types of grenades to be use in modern warfare.

meters in the shape of a half-circle, and travel forward and sideways after the bursting of the grenade, but none are driven backward toward the thrower. These grenades are consequently of great value for fighting at close quarters. They are so constructed as to be secure from bursting until they have traveled at least 8 meters on their way toward the target.

C. A single volley of 7 hand grenades, namely, 3 of type $A 1$ and 4 of type $C$, thrown by hand from behind covers at the targets shown in sketch. Result: 119 hits on 33 targets as shown by the numerals on the latter. The hand grenade, type $A 1$, weighs about 1 kilolatter. The hand grenade, type $A 1$, weighs about 1 kilo-
gramme, contains 190 bullets of 2.4 grammes each and a charge of 110 grammes of explosive (Ecko). The percussion mechanism and safety arrangements are sim lar to type $C$, but the bullets fly in all directions on the bursting of the grenade, consequently it is only suitable for throwing from behind cover.

$D$. Three mine grenades were buried underground in a triangle at 30 meters interval in the midst of a group of about 145 double-figure targets of wood, which were distributed over an area of about 2,700 square meters. The grenades were fired singly, one after the other (by electricity), and the results were about $\mathbf{7 0 0}$ hits among 120 targets, as shown by numerals.

The mine grenade weighs about 4 kilogrammes and contains 400 projectiles each weighing 3.3 grammes and 200 grammes of explosive (Ecko). The 400 projectiles cover a beaten zone of at least 800 square meters. The grenades are buried about half a meter underground, together with the electrical connections, so that they are absolutely invisible to an enemy. On being fired they rise about three fourths of a meter above ground before bursting and their projectiles are then driven in all directions parallel to the ground sur- reached an intensity of 6 , or possibly 7, on the Rossi-Forel scale. At Binghamton, Penn Yere thrown about, and a mild panic occurred among were thrown about, and a mild panic occurred among
the inhabitants. In Manhattan very few people were the inhabitants. In Manhattan very few people were
conscious of the shock, but it was distinctly perceptible conscious of the shock, but it was distinctly perceptible
in parts of Brooklyn, owing evidently to local instability of the soil. After-shocks were reported from New England on the 11th.

The whole phenomenon was one which would have attracted little attention if it had occurred in one of the great seismic belts of the earth. Happily macroseisms are rare in the eastern United States; though the presence of extensive fault-lines running practically the whole length of the Appalachian Valley, and northward makes it certain that perceptible and perhaps locally destructive earthquakes will occur in this comparatively favored part of the world from time to time in the future as they have in the past. Their effects will depend upon surface texture. The same intensity of impulse that wrought serious disaster in Charleston, S. C., in 1886, would probably leave New York. city unscathed; the former town being built on soft and largely "made" land; the latter on thoroughly consolidated soil and rock.

Mine Disasters in the United States.-The statistics of coal-mine fatalities in the United States during last August, just published by the Bureau of Mines, show 230 deaths, as compared with 211 during the same month of 1912. During the first eight months of 1913, the fatalities numbered 1,673 , as compared with 1,589 during the corresponding period of 1912 . These shocking figures emphasize the importance of the humanitarian activities and investigations in which the Bureau of Mines has taken the lead. 


\section{The Value of Radium}

TO scientific men radium has been a subject of abTorbing discussion from the moment it was discovered, but it is rapidly becoming a matter of considerable interest to the general public on account of its therapeutic value. Its extreme rarity and the mysterious and not yet wholly understood qualities and activities which are peculiar to it, added to the enormous difficulty in obtaining even small quantities of the precious metal, and the extraordinary prices quoted for it when obtained, invest the subject with a glamor which appeals to the romantic side of human nature. Consequently, every fact concerning radium, and every fresh development of our knowledge of its properties, are noted with intelligent curiosity by the great majority of newspaper readers, to whom chemistry is a closed book and physics a matter of no concern.

Its recent effects in the treatment of cancer have called forth manifestations of world-wide satisfaction, and "radium water" is now being tried for the treatment of gout and rheumatism. This is the ordinary fluid known to chemists as $\mathrm{H}_{2} \mathrm{O}$, and to the layman as simply "water," but it is charged with the emanation, or gas given off by radium in the form of radium salts. The method of preparation is to dissolve the salts in water, which is then sealed up and left for about 28 days, during which the emanation is produced. It can then be expelled by boiling and passed into another measure of water, endowing the latter with radio-active qualities. Unfortunately, this radio-activity only endures for a short time, and in $\mathbf{9 6}$ hours, or thereabout, the preparation has diminished in efficiency by more than fifty per cent. Water with a certain amount of inherent radio-activity can be obtained from springs, and dust with the same characteristics is also found in certain localities. In those cases the water must be drunk fresh from the spring, but the dust appears to retain its curative quality as a dressing for wounds or otherwise therapeutically, in the form of plasters and poultices, for a considerable time after removal from the spot where it is found and when it has been subjected to the influence of radium in the ordinary course of nature. In Great Britain, and presumably elsewhere, the usual course adopted in treatment of disease by radium water is to make up for the diminishing effect by increasing the quantity taken as the treatment proceeds, and as the water prepared thus is producible at a cost which is infinitesimal as compared with that of radium itself, it promises, if successful, to be a boon to suffering humanity.

It is to be hoped that as our knowledge of the effects of radium on cancer increases we may find some cheaper method of extracting it from the substances which contain it, for at present the cost of the process is simply prohibitive. So far it has been found in pitch-blende, autunite, carnotite and torbenite, owing to their containing small quantities of the metal uranium, which itself contains the much sought-for radium in the proportion of $1 / 3,000,000$.

A ton of the ore above referred to will contain some ten milligrammes of radium and Madame Curie's standard sample contains twenty-two milligrammes of pure radium chloride. European transactions in this valuable product usually include an agreement providing that the article delivered shall be compared with the standard at Sevres or the analogous standard at Vienna in the keeping of the Austrian Academy of Sciences.

The current market value of radium in Europe at the present moment works out at somewhere about $\$ 2$,500,000 per ounce-not that any individual or corporate society is fortunate enough to be in possession of such a quantity.

\section{How a Cream Separator Speed Indicator} Saves Money

6T HERE! If you've been turning your separator

at that speed all the time, then with your twenty cows you've lost $\$ 524.10$ worth of butter in one year!" The above is the astounding statement made by a dairying authority to a farmer whom he had been watching operating his cream separator.

When you buy a cream separator you will find on the crank handle, in large, raised letters instructions something like this-" 55 revolutions per minute." or it may read 45, or 50, or 60 ; it varies on the different makes of separators.

Suppose, for example, that yours reads "55 revolutions per minute." What does that mean? It means, whenever you operate that cream separator you should turn the crank handle precisely 55 turns to the minute.

The manufacturer has tested his separator under every possible condition, in order to know the exact method of operation at which it gives the greatest degree of efficiency.

But how does the dairyman know how many times he turns it? It is just as impossible to guess accurately the speed of his cream separator as it is to guess ccurately at other things.

At a first-class dairy farm the superintendent sald he always "guessed" the proper speed. When asked how his helpers operated the separator he replied that, after he had broken new men in, they also could operate it at approximately correct speed. In order to prove his statement, one of his helpers was asked to turn the separator at the speed he usually operated it. Th number on the crank handle read "48 revolutions pe minute." But the helper made only 28 turns to the minute.

This proved how absolutely wrong the superintendent was in supposing that he, or any of his helpers, could tell when they were turning the crank handle exactly right, or anywhere near, what the manufacturer told them it should be turned. Here were pound of butter-fat going to the hogs daily, just because he "guessed." And if he will feed calves and hogs with butter-fat worth 30 cents a pound, when he can feed them better on two and one half pounds of corn meal and skim milk, then that shows how much the dairymen have to learn to get all the profits out of dairying and farming.

At the Purdue Experiment Station, Indiana, very ex haustive tests were carried on to show the tremendous losses through wrong operation of cream separators. A separator was run at its normal speed of 55 turns to the crank handle per minute. Fifty pounds of milk were run through the separator. At this speed, it delivered 45 pounds of skim milk and 5 pounds of cream. This cream tested 2.11 pounds of butter-fat. When the speed was increased to 75 turns per minute, the skim milk discharged was $461 / 2$ pounds, reducing the cream to $3 \frac{1}{2}$ pounds. And the amount of butter-fat was slightly less than when the separator was turned at normal speed.

Next, a test was made by letting the speed of the machine drop down to that at which it has been foun the average dairyman operates a cream separator, with the astonishing result that the discharge from the "cream" spout went up to $91 / 2$ pounds, but it tested only 11 per cent of butter-fat-only 1.04 pounds of fat out of 50 pounds of milk, as against 2.11 pounds when the separator was operated correctly.

Dairymen are losing from 20 to 50 per cent of their butter-fat with every operation. This is a matter of waste that is simply appalling when the aggregate figures of all the dairymen in this country are considered. It probably runs into thousands of dollars with each daily milking.

Now a speed indicator has been invented to be applied to cream separators, mounted on the crank shaf of the separator. As the separator handle is turned, the exact number of revolutions per minute that the crank handle is making is shown in a definite figure, so that it may be read at a glance. There is no calculating to be done; it is only necessary to keep on turning the crank handle until the proper speed is reached, and then continue at that exact speed throughout the separation. This eliminates all guess-work entirely. It also adds zest to the otherwise monotonous operation, an hour's turning, as its does in many instances.

\section{Is the Earth Drying Up?}

$\mathrm{N}$ a recent paper before the Royal Geographical Society Prof. Gregory discusses this question. It is believed by many that there is a progressive world-wide change toward a greater and greater degree of dryness. Prof. Ellsworth Huntingdon believes that there ar alternations of climate, it being sometimes drier, sometimes moister, but with a tendency to become generally dried. Mr. R. Thirlmere believes that the climatic changes take place in cycles, each cycle lasting 2,000 years or more, and that our world is at present cooling. From an exhaustive analysis of the evidence Prof. Gregory doubts the theory of a universal tendency to ward drought, although there may be local variations The strongest evidence for the desiccation theory is derived from Central Asia, the majority of travelers who have visited that region being convinced of its progressive change to a state of greater and greater dryness.

Absorption of Light in Space.-If one divides the known nebulæ in groups according to the dimension of their apparent diameters and one also notes their intrinsic brightness, it is clear that their apparen diameters should decrease as the distance increases. Their brightness, on the other hand, will diminish with increasing distance only if interstellar space absorbs light. As the result of a great number of observations light. As the result of a great number of observations a correlation between brightness and apparent diameter
has been observed, and is so marked that it is impossible to put it down to chance or to some systematic erro It appears that there is a real absorption in space, and if more precise descriptions of the nebulæ were available the law of absorption could be assigned. Another indication in the same direction is that the mean brightness of the nebulø varies from one part of the heavens to of the nebulm varies from one part of the heavens to
another in a marked manner and in the same way as another in a marked
the stellar density.

\section{Trarregpanitentp}

[The editors are not responsible for statements made in the correspondence column. Anonymous comcorrespondents will be withheld when so desired.]

\section{A Problem in United States Coins}

To the Editor of the Scientific American :

Permit me to offer the following solution to the problem submitted by Theodore L. DeLand in the Scientific AMERICAN of February 7th, on page 117, and entitled "A Problem in United States Coins." I have not yet thought of an algebraic formula by which the problem could be solved, but have reasoned it out by a process of elimination.

The highest common factor of 200 , the number of coins, and 50,000, the value of those coins in cents, without making the resulting quotient approximately equal to or less than the number of different kinds of coins, which would be absurd, is 10 . The resulting quotients are 20 (coins) and 5,000 (cents). Hence, if twenty coins can be found, subject to the condition stated, whose combined values are 5,000 cents, it will only be necessary to multiply the number and the value of each kind by 10 and add the resulting similar products to get 200 coins. and $\$ 500$ for the final result.

Considering only the four gold coins now minted, there are only ten possible combinations in which the values are less than 5,000 cents. If the number of coins in each combination be subtracted from 20 and their value from 5,000, it will be found that four of the possible ten combinations can be eliminated, because if all the coins in each case were fifty-cent pieces, the largest coin now left to be considered, their combined values would not be as large as the required value in the given combination. Therefore, only the following six possible combinations remain to be considered :

No. of coins. Value in cents. No. of coins. Value in cents.

$\begin{array}{llll}15 & 250 & 14 & 500 \\ 15 & 500 & 13 & 500 \\ 15 & 750 & 13 & 250\end{array}$

By the same line of reasoning I took up each of the above combinations separately, and from the 15 to 250 one derived a 10 to 50 combination in which only dimes, nickels and cents had not yet been considered -4 dimes, 1 nickel and 5 cents make such a combination. Working back through the proper combination, $I$ found that I had used 5 cents, 1 nickel, 4 tens, 2 quarters, 3 fifties, $1(\$ 2.50), 1(\$ 5), 2(\$ 10)$, and $1(\$ 20)$.

Multiplying by 10 as determined in the second paragraph above, I summed up as follows :
50 cents
$\$ 0.50$
10 nickels
.50
20 quarters
4.00
5.00
30 fifties
$10(\$ 5)$
20 (\$10)
15.00
$10(\$ 20)$
50.00
coins
$\$ 500.00$ Teacher of Physic
DWARD D. ARNoLd,

Ithaca, $\mathbf{N}$. Y.

\section{Snow Rollers}

To the Editor of the Scientific American :

About a year ago I wrote you concerning some "Snow Rollers" which had formed on our lawn at Potsdam, N. Y. The article was published and caused a little comment at the time. I thought it might be of interest that the "rollers" have again made their appearance, in the same place, though in smaller numbers. It is a curious fact that in no previous year has this phenomenon been observed here, and now it has appeared twice in succession.

Middletown, N. .Y.

T. J. MooN.

\section{The Salving of Submarines}

To the Editor of the ScIENTIFIC AMERICAN :

The daily press records the sinking of a submarine of the navy of Great Britain; and the fact that no provision is or has thus far been made for supplies while a boat is submerged, leads me to suggest the idea that comes to my mind in connection.

Were a length of hose contained in the submarine boat to pass through a hole in the top provided for the purpose, and the hose end connected with apparatus lighter than water, would it not be possible to- 